\title{
Discriminative Stimulus and Low Abuse Liability Effects of Novel Endomorphin Analogs Suggest a Potential Treatment Indication for Opioid Use Disorder
}

\author{
Mark R. Nilges, Morgan Laurent, Chloe Cable, Louis Arens, James Vafiades, \\ and James E. Zadina \\ Southeast Louisiana Veterans Health Care System (J.E.Z.), Departments of Medicine (J.E.Z.), Neuroscience (M.R.N., M.L., C.C., \\ L.A., J.V., J.E.Z.), and Pharmacology (J.E.Z.), Tulane University School of Medicine, New Orleans, Louisiana \\ Received August 17, 2018; accepted May 28, 2019
}

\begin{abstract}
Opioid dependence can be difficult to manage using existing pharmacotherapies. A long-acting opioid with low abuse liability that substitutes for a shorter-acting opioid may improve treatment of opioid use disorders (OUDs). We recently characterized an endomorphin (EM) analog (ZH853) that produced a longer duration of antinociception compared with morphine, but did not produce self-administration or several other adverse effects preclinically. Here, we further characterized ZH853 in tests of antinociception, abuse liability, and drug discrimination. A conditioned place preference (CPP) procedure, that included a locomotor activity assessment, was used to test abuse liability in rats. Subsequently, dopamine (DA) cell-somas located in the ventral tegmental area (VTA) from these rats were assessed by size using immunohistochemistry and Stereo Investigator software. A hot-plate antinociception test in male and female mice confirmed central penetration. Morphine-substitution effects of several EM analogs (ZH850, ZH831, and ZH853) were tested in a drug discrimination (DD) procedure in rats. Morphine produced dose-dependent CPP and locomotor sensitization and reduced
\end{abstract}

the size of DA cell somas in VTA, whereas ZH853 did not produce any of these effects relative to control. The antinociceptive effects of ZH853 were $\mu$-receptor selective since $\beta$-funaltrexamine antagonized these effects. Rats responded on a morphinetrained lever when injected with $\mathrm{ZH} 831$ and $\mathrm{ZH} 853$ during DD experiments. The favorable morphine-substitution effects of these EM analogs relative to their low abuse liability indicate promising novel compounds that may improve treatment of OUD.

\section{SIGNIFICANCE STATEMENT}

In this experiment, we investigated the preclinical effects of novel endomorphin analogs for use as substitution therapies for opioid use disorder, a problem that has contributed to an opioid overdose epidemic. Several endomorphin analogs substituted for morphine without producing adverse effects, including reward behaviors associated with abuse liability. These compounds have the potential to become important additional tools to treat opioid use disorders.

\section{Introduction}

Opioid abuse and dependence are widespread problems that cause devastating health consequences. Opioid overdose deaths have more than doubled over the past 10 years, in part because of coabuse of prescription opioids, heroin, and/or fentanyl (https://www.drugabuse.gov/related-topics/trends-statistics/ overdose-death-rates). Opioid use disorders (OUDs) are routinely treated with a full $\mu$-opioid receptor (MOR) agonist, such as methadone, or a partial agonist, such as buprenorphine, for substitution therapy; however, these compounds

This research was financially supported by a Merit Review Award [I01 BX003776] from the Department of Veterans Affairs, grants from the Department of Defense [Grant DM090595], Office of Naval Research [Grant N00014-09-1-0648], the Louisiana Board of Regents [Grant ITRS-015B] to J.E.Z., and a Board of Regents predoctoral fellowship to M.R.N.

https://doi.org/10.1124/jpet.118.253013. are tightly regulated because they have their own propensity for abuse indicated by robust intravenous self-administration (SA) rates, locomotor sensitization, and conditioned place preference (CPP) behaviors in rats (Steinpreis et al., 1996; Tzschentke, 2004; Martin et al., 2007; Wade et al., 2015). In humans, buprenorphine and methadone have clinical utility for reducing the positive subjective effects of opioids, but both these compounds are self-administered and produce positive reinforcing effects (Comer et al., 2005; Jones et al., 2014). Novel substitution therapies with low abuse liability compounds may improve the treatment of OUD.

Endomorphins (EMs) are endogenous tetrapeptides that are highly selective for the MOR (Zadina et al., 1997), the primary analgesic target for opium-derived medications such as morphine. Recently, we described four cyclized D-amino acid-containing EM analogs with reduced or absent adverse

ABBREVIATIONS: ANOVA, analysis of variance; $\beta \mathrm{FNA}, \beta$-funaltrexamine; BBB, blood-brain barrier; CNS, central nervous system; CPP, conditioned place preference; DA, dopamine; DD, drug discrimination; EM, endomorphin; FR, fixed ratio; LS, locomotor sensitization; M, morphine; MOR, $\mu$-opioid receptor; MPE, maximum possible effect; NAc, nucleus accumbens; OUD, opioid use disorder; PBP, parabrachial pigmented area; PBS, phosphate-buffered saline; SA, self-administration; TH, tyrosine hydroxylase; V, vehicle; VTA, ventral tegmental area. 
effects relative to morphine. Furthermore, we characterized a lack of glial reactivity by these analogs that may account for their favorable analgesic effects and low adverse effects. Our prior study showed favorable antinociceptive profiles for four EM analogs (1 = ZH850, 2 = ZH831, 3 = ZH809, 4 = $\mathrm{ZH} 853$ ). One of these ( $\mathrm{ZH} 853)$ provided the longest antinociceptive duration and greatest reduction of all side effects tested, including respiratory depression, motor impairment, tolerance, glial reactivity, and abuse liability (Zadina et al., 2016). ZH853 was not self-administered in a sensitive long-access SA model, nor did it produce CPP, suggesting an absence of operant and conditioned reinforcing effects. Chronic intrathecal infusion of ZH853 produced significantly less antinociceptive tolerance than morphine and did not activate spinal dorsal horn glial cell markers that were upregulated in animals infused with chronic morphine. ZH853 has become our lead compound as a potential novel analgesic.

Here we assessed the suitability of ZH853 for OUD using five approaches: 1) an extended (5-day) CPP procedure; 2) an examination of locomotor sensitization, a behavior associated with increased dopamine (DA) release (Bohn et al., 2003) and abuse liability (Robinson and Berridge, 2001); 3) examination of BBB penetration and $\mu$-selectivity of ZH853; 4) an assessment of a potential neurobiological rewardtolerance mechanism by which repeated morphine injections reduce the size of ventral tegmental area (VTA) DA neurons (Kish et al., 2001; Chu et al., 2008; Mazei-Robison et al., 2011; Mazei-Robison and Nestler, 2012); and 5) an examination of the interoceptive stimulus effects of ZH831, ZH850, and $\mathrm{ZH} 853$ in a drug discrimination (DD) procedure. An ideal combination of properties for OUD treatment would be a compound that would not induce multiple indices of abuse liability (including CPP, SA, or locomotor sensitization) or reduce the size of VTA DA neurons but would penetrate the blood-brain barrier (BBB) and provide discriminative stimulus effects that are similar to an illicit opioid such as morphine. An important property of a candidate compound for substitution therapy is that the patient experience it somewhat similarly to the abused agonist. Typically, a partial agonist meets these requirements while producing fewer reinforcing effects. Although DD is typically used to indicate that the test drug may be abused if subsequent CPP or SA tests confirm abuse liability (Swedberg, 2016), it may also indicate that the test drug is similar to the training drug but dissociable from the reward properties of the training drug (Ator, 2002), as is the case with the nicotine replacement therapy, varenicline (Bordia et al., 2012), the active ingredient in Chantix (Pfizer, New York, NY). Methadone, and buprenorphine have played a valuable role in the treatment of OUD. They produce effective opioid substitution effects with relatively long durations of action that can reduce the need for subsequent doses. These compounds do, however, retain reward properties. Novel therapies lacking reward properties could therefore increase the armamentarium of options for the treatment and management of OUD. This series of experiments assessed several indices of the abuse liability of ZH853 and the discriminative stimulus effects of ZH853, as well as two structurally-related EM analogs (ZH831 and ZH850) to determine their potential as novel treatments for OUD.

\section{Materials and Methods}

\section{Animals}

Male Sprague Dawley rats were purchased from Charles River (Wilmington, MA) and housed in a 12 hours light/dark cycle at $22^{\circ} \mathrm{C}$ with $30 \%-70 \%$ humidity. Rats arrived at 3 months old weighing approximately $260-300 \mathrm{~g}$ and were housed two per cage until surgery. After surgery, rats were singly housed. For the hot-plate study, DBA male and female mice were purchased from Charles River and housed under a 12-hour light/dark cycle at $22^{\circ} \mathrm{C}$ with $30 \%-70 \%$ humidity. Mice weighed approximately $20-25 \mathrm{~g}$ and were housed four to five per cage. All experiments were approved by the Tulane Institutional Animal Care and Use Committee and conducted according to the NIH Guide for the Care and Use of Laboratory Animals.

\section{Drugs}

EM analogs were synthesized by standard solid-phase methods at $1 \mathrm{mmol}$ on a Rink amide resin via Fmoc chemistry with purity (>95\%) and sequence identity confirmed by high-performance liquid chromatography and mass spectrometry. Analogs selected for full characterization and used here were synthesized at 2- to 4-g scale by American Peptide Company/Bachem (Torrance, CA), including Tyr-c[D-Lys-TrpPhe-Glu]-NH 2 (ZH850), Tyr-c[D-Glu-Phe-Phe-Lys]-NH $\mathrm{NH}_{2}$ (ZH831), and Tyr-c[D-Lys-Trp-Phe-Glu]-Gly-NH $\mathrm{NH}_{2}$ (ZH853) (Zadina et al., 2016). Morphine sulfate was supplied by the National Institute on Drug Abuse, $\beta$-funaltrexamine ( $\beta$ FNA), and naloxone were obtained from Sigma (St. Louis, MO). Morphine sulfate and $\beta$ FNA were dissolved in saline and ZH850, ZH831, and ZH850 were dissolved in $20 \%$ polyethylene glycol/saline.

\section{Intravenous Catheter Implantation}

Rats were catheterized in the left jugular vein (Wade et al., 2015; Zadina et al., 2016). Rats were anesthetized with an isoflurane/oxygen mixture (4\% to $5 \%$ induction and $1.5 \%-2.5 \%$ for the remainder of the surgery). A 1-cm area on the ventral and a $2-\mathrm{cm}$ area on the dorsal side of the rat were shaved and sterilized for incision. The catheter was passed subcutaneously from the back, inserted into the left jugular vein, and secured with sutures. Wounds were sutured and dressed using antibiotic ointment, and rats were given a subcutaneous injection of $0.5 \%$ lidocaine and $0.25 \%$ bupivacaine for incisional pain. All rats were allowed 5 days to recover from surgery before behavioral testing began. Catheters were flushed every other day with $0.1 \mathrm{ml}$ of streptokinase $(0.134 \mathrm{mg} / \mathrm{ml})$ to maintain catheter patency. Rats with questionable catheter patency were tested with an injection of the ultra-short-acting barbiturate anesthetic, methohexital $(0.1 \mathrm{ml}$ of $10 \mathrm{mg} / \mathrm{ml}$ ). If muscle tone was not lost within 3 seconds, the catheter was considered faulty and the rat was excluded from the analysis.

Experiment 1: Conditioned Place Preference and Locomotor Activity. Standard CPP chambers (TSE, Chesterfield, MO) were used to measure baseline activity and conditioning trials. Baseline activity was measured over 2 days with four trials per day (two in the morning, two in the evening) lasting 20 minutes each. Conditioning trials were conducted immediately after injection of morphine, ZH853, or vehicle, and rats were restricted to distinct compartments (striped vs. gray walls) for 30 minutes. Doses of morphine or ZH853 (1.8, 3.2, and $5.6 \mathrm{mg} / \mathrm{kg}$, i.v.) were chosen based on antinociceptive percent maximum possible effect (\%MPE) levels of $70 \%-80 \%, 100 \%$, and a $1 / 4 \log$ dose higher, respectively (Zadina et al., 2016). Conditioning trials were conducted for 5 days and tested in an unbiased manner such that drug/environment pairings were counterbalanced for the time of drug injection (morning or evening) and compartment (preferred or nonpreferred) based on baseline activity. Analysis of data from our previous study using this design in a 3-day paradigm (Zadina et al., 2016) showed no difference in the effects of morning versus evening administration of ZH853 and no interaction of drug dose $\times$ time of administration on CPP scores. This indicates a lack of carryover effects of drug between sessions. 
One day after the last conditioning trial, a 20-minute test trial was conducted in the same manner as baseline trials in which rats were free to explore both compartments. Change in time spent exploring the drug-paired compartment (test-baseline) was used to indicate preference (or aversion) to the compartment. Approximately 20 minutes after the final session, rats were perfused, and brain samples were taken for immunohistochemical analysis (to follow).

Locomotor activity was assessed by infrared light beams located in the conditioning compartments and the start box. Locomotor activity was assessed during conditioning with morphine, ZH853, or vehicle immediately after injection for the entire duration of the five daily conditioning trials and during test sessions in which no drug injections were made. Data were recorded in meters, and an assessment of locomotor sensitization was made by subtracting the first session from the final session.

Experiment 2: DA Morphology Analysis. Fifteen minutes after the final CPP test session, rats were anesthetized with a mixture of ketamine/xylazine $(85 / 10 \mathrm{mg} / \mathrm{kg}$, i.p., respectively) and perfused intracardially with $200 \mathrm{ml}$ of $0.1 \mathrm{~mol} / \mathrm{l}$ phosphate-buffered saline (PBS), followed immediately by $300 \mathrm{ml}$ of $4 \%$ paraformaldehyde in $0.1 \mathrm{~mol} /$ liter $\mathrm{PBS}(\mathrm{pH}=7.4)$. Brains were removed and postfixed at $4^{\circ} \mathrm{C}$ in the same fixative for 18 hours. After postfixation, brains were incubated in $30 \%$ sucrose at $4^{\circ} \mathrm{C}$ for 2 days and sectioned coronally on a cryostat at $40 \mu \mathrm{m}$ at the level of the posterior VTA (Spiga et al., 2003; Chu et al., 2008). After two consecutive washes in PBS, sections were blocked with 5\% normal donkey serum for 1 hour and incubated with the primary antibody anti-tyrosine-hydroxylase (anti-TH, 1: 3000; Cell Signaling Technology, Danvers, MA) overnight at $4^{\circ} \mathrm{C}$. Slices were washed twice in PBS, reblocked for 1 hour, and incubated with the secondary antibody Alexa594 (Life Technologies, Carlsbad, CA) for 2 hours. Sections were washed, mounted on slides with Prolong Gold (Life Technologies), and stored at $4^{\circ} \mathrm{C}$. Posterior VTA sections were verified according to the atlas of Paxinos and Watson (2007). Images of the parabrachial pigmented area (PBP) and the paranigral area subregions of the posterior VTA were captured in z-stacks $(1 \mu \mathrm{m})$ with at least five tissue slices per rat and five to six rats per drug group. Stereo Investigator software (MBF Bioscience, Williston, VT) was used to quantify soma size using the optical fractionator probe to survey a sample of neurons in each z-stack; the nucleator probe was used to measure the crosssectional area and volume of each cell soma. The optical fractionator probe was used to quantify the number of cells in a specific section of tissue through systematic random sampling. Between 12 and 16 regions were surveyed per z-stack. The optical fractionator probe used stereological techniques to select a random sample to be analyzed, and the nucleator probe measured the cross-sectional area of each neuron. Therefore, simultaneous use of these probes systematically assessed neurons in the PBP and paranigral area regions of the VTA in each subject and provided morphologic data for these cells, including surface area (square micrometers) and volume (cubic micrometers). Cell somas were eligible to be quantified if they were located within the counting frame or the soma touched either of the nucleator frame's green borders. Neurons were ineligible if located outside the counting frame or if their soma touched the frame's red borders. After determining this optimum depth, the center of the soma was located and analyzed by the nucleator probe. To eliminate bias associated with tissue orientation, nucleator rays were randomly arranged between quantifications. The nucleator probe accounted for tissue thickness and the cross-sectional area to determine the surface area and volume of cell somas. All images and data analysis were collected by a blinded investigator.

Experiment 3: Hot-Plate Test. The hot-plate (IITC, Woodland Hills, CA) antinociceptive test, which reflects a supraspinally organized complex response (Chapman et al., 1985), was used to assess the central nervous system (CNS) penetration of ZH853. The hot-plate apparatus was set to $55.5^{\circ} \mathrm{C}$, a temperature that elicited a response after 7-9 seconds. Three baseline hot-plate latencies to rapidly lift, lick, or shake the hind paws were taken before drug injection. Mice were removed from the hot plate after a maximum of 30 seconds. $\beta$ FNA or vehicle was injected 24 hours before hot-plate testing. Mice were then injected with ZH853 (0-10 mg/kg s.c.) and tested 30, 45, 60, $90,120,180$, and 240 minutes after injection. Data were converted to maximum possible effect (\%MPE) values by the following formula: ([latency - baseline latency]/[30-baseline latency])*100. These values were then converted to area under the curve for statistical analysis.

Experiment 4: Drug Discrimination (DD). Rats were food deprived to approximately $85 \%$ of the weight of free-feeding cohorts to establish operant responding for $45-\mathrm{mg}$ food pellets (Bioserve, Frenchtown, NJ) in standard operant chambers (MED Associates, St. Albans, VT). Rats were fed 10-20 g of standard food after daily DD sessions and $\sim 3 \times$ the daily amount on weekends to maintain appropriate weight. DD consisted of three phases (Krivsky et al., 2006). In phase 1 , rats were trained to lever-press for food at a fixed ratio (FR) level 1 (i.e., one lever press = one food pellet) using two levers with stimulus lights located above each lever and a food hopper between the levers during 120-minute sessions. Responding on either lever extinguished the light and delivered a food pellet. Once the rats earned 100 food pellets in the 120-minute session for two consecutive sessions, response requirements progressively increased to FR2, FR5, FR7, and FR9. Once $\geq 20$ pellets were earned at FR9, sessions were shortened to 20 minutes, response requirements were set at FR10, and the left or right lever reinforced responding on alternate days. Once $\geq 20$ pellets were earned on each lever at FR10, rats started phase 2 of DD training. Phase 2 consisted of pretreatment with vehicle or morphine $(3.2 \mathrm{mg} / \mathrm{kg}$, s.c.) 30 minutes before a 20 -minute session, and food pellets were available only on the vehicle (saline) or morphine lever, as indicated by a light above the lever. Half the rats were trained with morphine on the left lever and vehicle on the right; the other half were trained vice versa. The daily order of vehicle (V) or morphine (M) injections were rotated on a 4-week cycle: week 1: M, V, V, M, V; week 2, V, M, M, V, M; week 3: V, V, M, M, V; week 4: M, M, V, V, M. When $\geq 20$ pellets were earned on both morphine and vehicle days, both stimulus lights were illuminated such that only the injection prompted lever responding. Only responses on the correct lever were reinforced, and responses on the incorrect lever reset the response requirement on the correct lever. Criteria to move to phase 3 were as follows: $\geq 20$ pellets per session, $\geq 90 \%$ injection appropriate lever responding, and $\leq 9$ responses on the incorrect lever before the first food pellet reward. At this point, substitution tests of subcutaneous morphine were conducted in which a range of morphine doses $(0,0.3,1$, $1.8,3.2 \mathrm{mg} / \mathrm{kg}$ ) were administered on Mondays and Thursdays, when pressings on either lever were reinforced, and training sessions were administered on the intervening days. Test session pretreatment times were the same as phase 2, with morphine, ZH850, ZH831, ZH853, or control injections made 30 minutes before a 20 -minute test session.

After completion of the subcutaneous dose response for morphine, intravenous catheters were implanted as described already herein. Training sessions continued using the intravenous route with a $1 / 4 \mathrm{log}$ lesser dose of morphine $(1.8 \mathrm{mg} / \mathrm{kg})$ because the antinociceptive potency of intravenous morphine is slightly greater than that of the subcutaeous route (South et al., 2009). Two paradigms were used to generate substitution curves: cumulative within-session and bolus between-session injections. For the between-session procedure, substitution curves were generated for morphine, ZH850, ZH831, and ZH853 (0, 0.3, 1, 1.8, 3.2, $5.6 \mathrm{mg} / \mathrm{kg}$, i.v.) in a computer-randomized order on Mondays and Thursdays using the intravenous route; food reinforcement occurred after meeting the FR10 requirement on either lever. Training sessions were administered on the intervening days to ensure that accurate responding and substitution tests occurred only after rats met the criteria described here for 4 days and met the criteria on the most recent vehicle or morphine training session. During substitution tests, both levers actively delivered food at an FR10 schedule. The cumulative injection model was conducted within a single session with morphine, ZH850, ZH831, and ZH853 or vehicle (Varner et al., 2013). Doses were increased in $1 / 4$ log increments, with 
injections every 20 minutes followed 15 minutes later by DD sessions lasting 5-minute each. Doses of morphine, ZH850, ZH831, or ZH853 were increased cumulatively by injecting $0.3,0.7,0.8,1.4$, and finally $2.4 \mathrm{mg} / \mathrm{kg}$ to achieve doses of $0.3,1,1.8,3.2$, and $5.6 \mathrm{mg} / \mathrm{kg}$. The advantage of this procedure was that an entire dose response was generated in one session.

\section{Statistics}

A one-way analysis of variance (ANOVA) with Newman-Keuls posthoc comparisons (GraphPad Prism, San Diego, CA) was used to compare CPP groups, locomotor effects, hot plate, and DD response rates. Locomotor data recorded during the conditioning sessions were analyzed by two-way ANOVA (session $\times$ drug), and data from the first session were subtracted from the final session to assess locomotor enhancement. Experimenters were blinded to treatment groups. DD data were analyzed by nonlinear regression to calculate the $\mathrm{ED}_{50}$ for morphine, ZH850, ZH831, and ZH853.

\section{Results}

Conditioned Place Behavior and Locomotor Effects of Morphine and ZH853. Daily morphine injections produced locomotor sensitization (LS) as measured by an increased distance traveled relative to controls [treatment effect: $F(3,28)=7.493, P=0.0008$; day effect: $F(4,112)=13.16$, $P<0.0001$; interaction: $F(12,112)=4.131, P<0.0001$ (Fig. 1A)]. The $1.8-\mathrm{mg} / \mathrm{kg}$ dose of morphine increased locomotion across all sessions, whereas higher doses (3.2 and $5.6 \mathrm{mg} / \mathrm{kg}$ ) initially suppressed locomotion, followed by a gradual increase that indicated LS (Robinson and Berridge, 2001). ZH853 did not produce LS at any dose tested $[F(4,36)=1.6$, $P=0.1956$, n.s. (Fig. 1B)]. When comparing the difference between day 5 and day 1 , morphine $[F(6,47)=7.635$, $P<0.0001$ (Fig. 1C)], but not ZH853, produced significant LS. Post-hoc comparisons showed that, compared with vehicle, morphine produced LS at all doses tested [1.8 and $3.2 \mathrm{mg} / \mathrm{kg}, P<0.001,5.6 \mathrm{mg} / \mathrm{kg}, P<0.01$ ], whereas $\mathrm{ZH} 853$ did not produce LS at any dose tested $(P<$ n.s. $)$. Morphine produced conditioned place preference $(\mathrm{CPP})$ effects after 5 days of conditioning $[F(3,25)=4.173, P=0.0159]$ with the $3.2-\mathrm{mg} / \mathrm{kg}$ dose $[P<0.05$ (Fig. 1D)]. The $1.8-$ and $5.6-\mathrm{mg} / \mathrm{kg}$ doses of morphine did not produce significant CPP, consistent with our 3-day injection model (Zadina et al., 2016). ZH853 did not produce CPP (or aversion) at any dose $[F(3,29)=$ $0.9523, P=0.4283$ n.s. (Fig. 1D)].

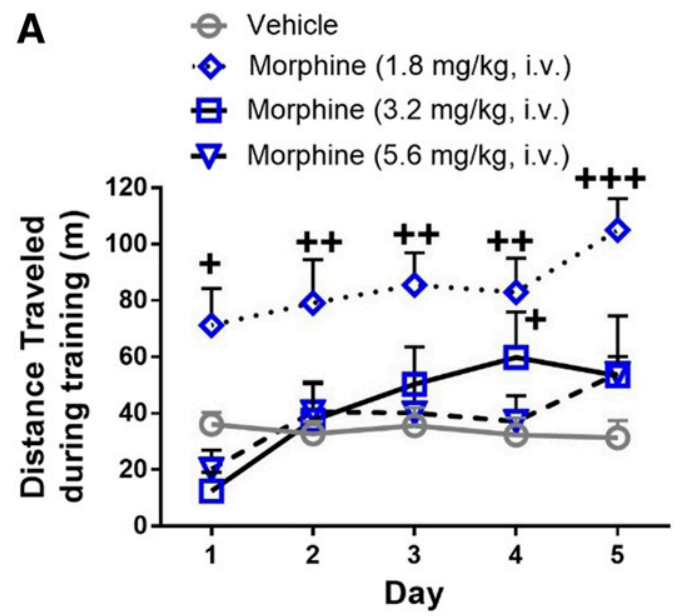

B
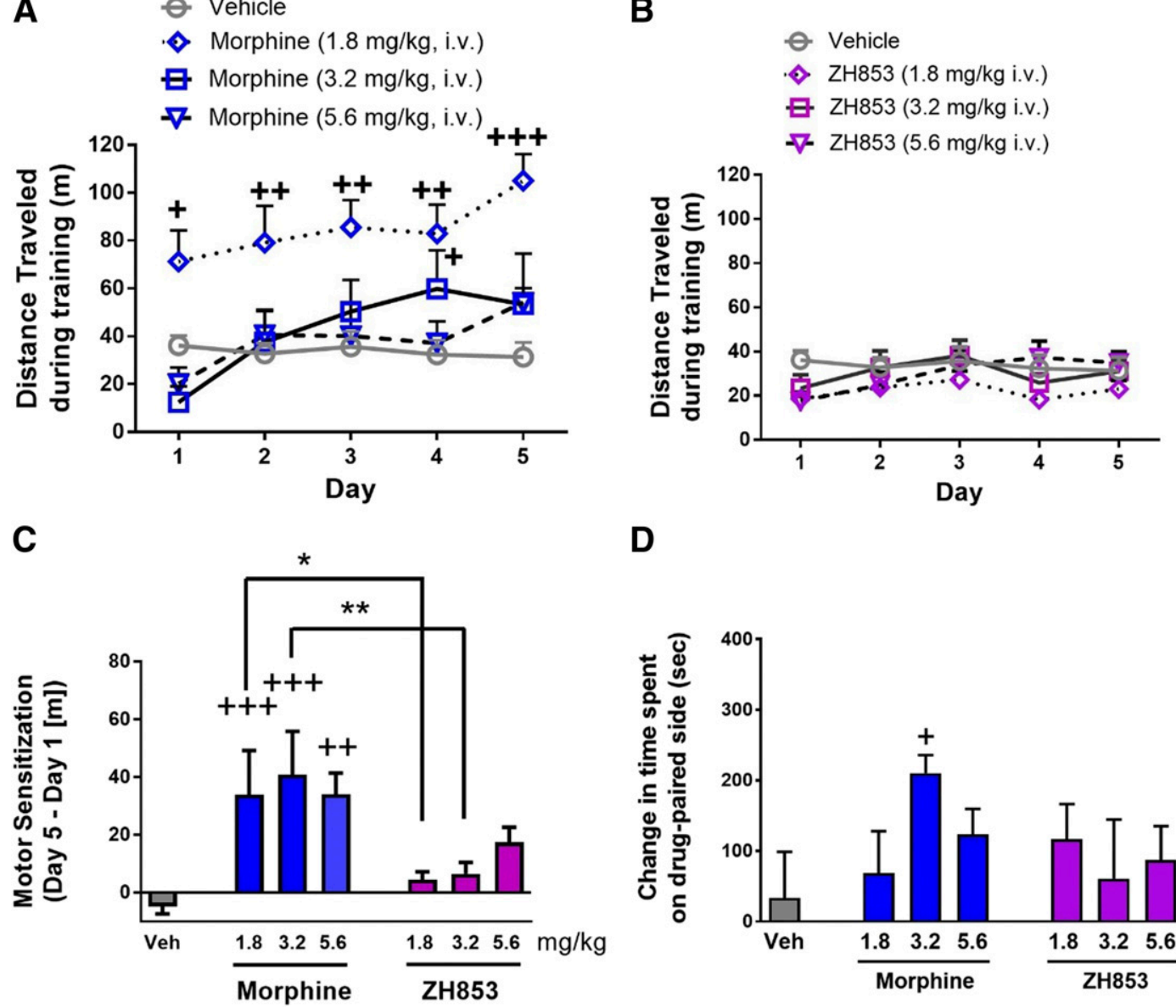

D

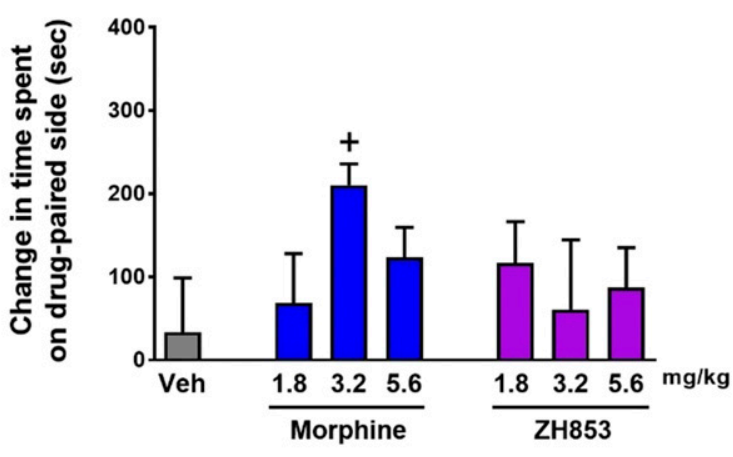

Fig. 1. Conditioned place preference and locomotor effects of morphine and ZH853. After establishing baseline activity, locomotor activity was measured during five daily conditioning sessions conducted immediately after intravenous injection of morphine, ZH853, or vehicle. (A) Locomotor effects of morphine differed by dose with lower doses producing acute locomotor enhancement, whereas higher doses (e.g., $3.2 \mathrm{mg} / \mathrm{kg}$ ) acutely suppressed locomotion and then enhanced locomotion after daily administration. (B) Locomotor effects of ZH853 were no different from controls. (C) Subtracting day 1 locomotion from day 5 shows that morphine produced locomotor sensitization, whereas EM ZH853 did not. (D) CPP effects after 5 days of conditioning shows that ZH853 did not produce CPP or aversive effects, whereas morphine (3.2 mg/kg i.v.) produced significant CPP. Nearly identical antinociceptive effects of morphine and ZH853 were produced during the same time frame that rats underwent CPP conditioning [see Zadina et al. (2016) for antinociception data]. ${ }^{+},{ }^{++},{ }^{++} P<0.05,0.01,0.001$ compared with vehicle; $*, * * P<0.05, P<0.01$ compared with morphine, respectively. 
VTA Dopamine Cell-Soma Morphology after Five Daily Injections of Morphine or ZH853. Rats injected with morphine for 5 consecutive days showed a dosedependent reduction in the size of dopamine (DA) neurons in the posterior VTA (Fig. 2A). Surface area $[F(2,27)=6.096$, $P=0.0065$, Fig. $2 \mathrm{~B}]$ and volume $[F(2,27)=4.185, P=0.0261]$ of TH-positive somas were reduced by morphine $(5.6 \mathrm{mg} / \mathrm{kg}$, $P<0.05)$. By contrast, ZH853 did not alter either surface area $[F(3,32)=0.9463, P=$ n.s. $]$ or volume $[F(3,32)=0.9590$,
$P=$ n.s.] of DA neurons in the pVTA as measured by Stereo Investigator software. Thus, daily injections of antinociceptive doses of morphine, but not ZH853, altered DA soma sizes in the pVTA.

Hot-Plate Antinociception after ZH853 and Reversal by the Selective MOR Antagonist $\beta$ FNA. ZH853 dose dependently increased reaction latencies on the hot-plate test in male DBA mice with maximal antinociception at a dose of $10 \mathrm{mg} / \mathrm{kg}$ (Fig. 3A). ANOVA showed significant effects of dose
A

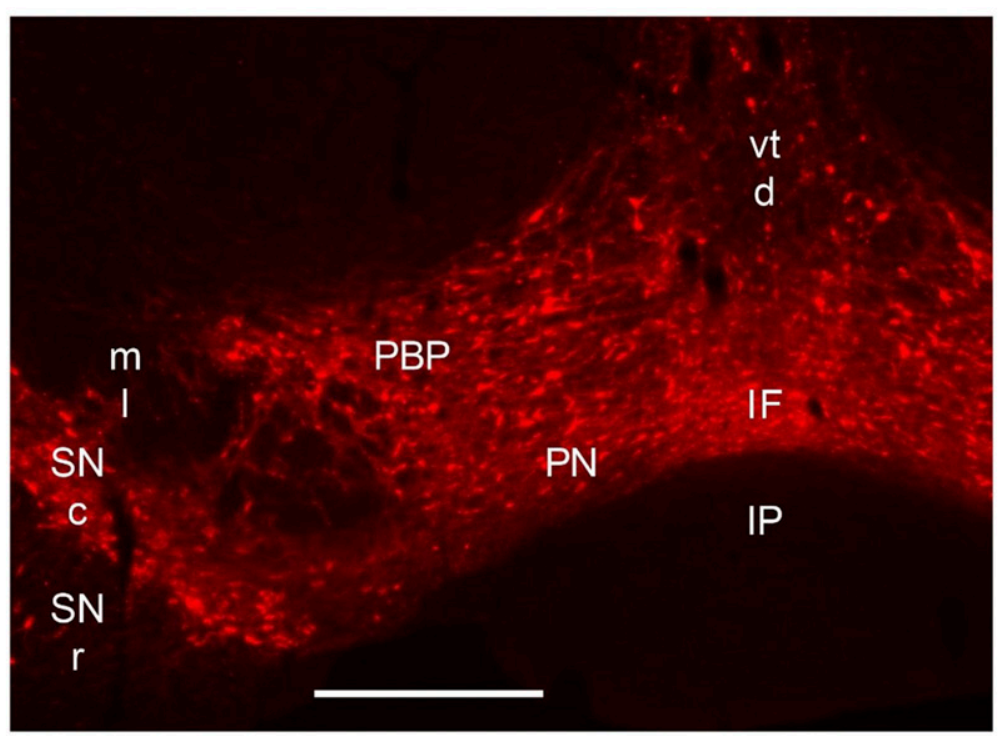

B

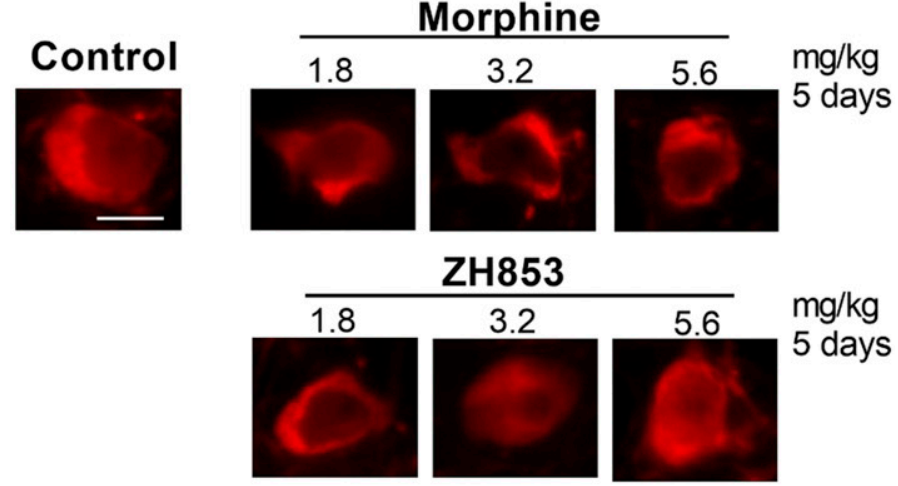

C
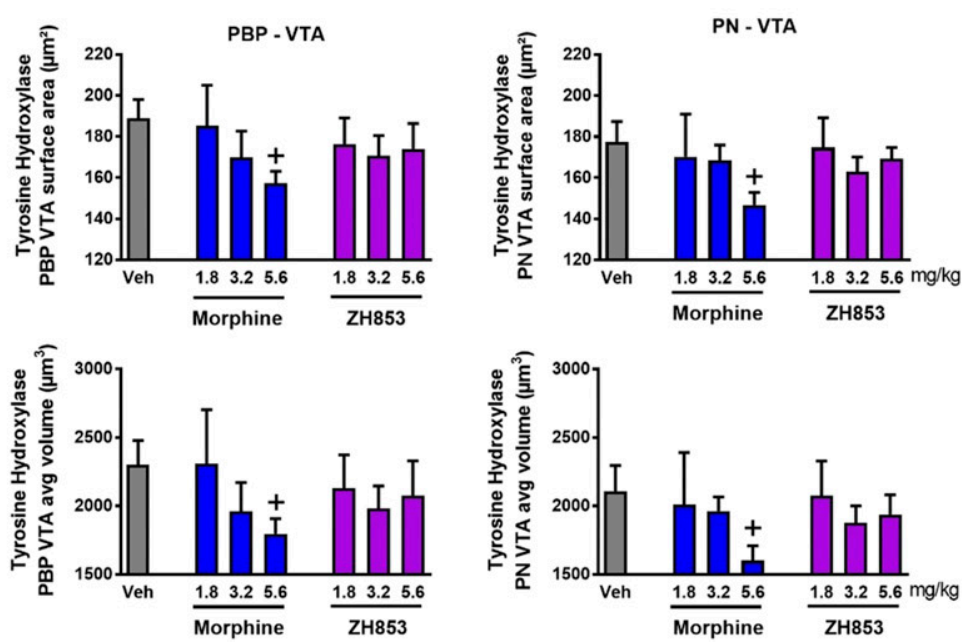

Fig. 2. Chronic injections of morphine, but not ZH853, reduced DA cell-surface area and volume in the posterior ventral tegmental area (pVTA). (A) Low-magnification section of pVTA used for analysis of DA morphology. Rats were perfused after the final CPP test session, and pVTA sections were stained with $\mathrm{TH}$. TH + somas from z-stacks were analyzed by MBF Stereo Investigator software for surface area (square micrometers) and volume (cubic micrometers) in the PBP and PN of the pVTA. (B) An example of PBP somas in which morphine $(5.6 \mathrm{mg} / \mathrm{kg}$, i.v.) reduced the surface area and volume of cell somas, whereas ZH853 did not alter soma sizes at any dose. (C) Surface area and volume of cell somas were quantified in PBP and paranigral area regions using the Stereo Investigator nucleator probe. Scale bars, $50 \mu \mathrm{m}$ (A) or $10 \mu \mathrm{m}$ (B). Six to eight cell somas were quantified per rat with five to six rats per drug group. $+P<0.05$ compared with vehicle. 

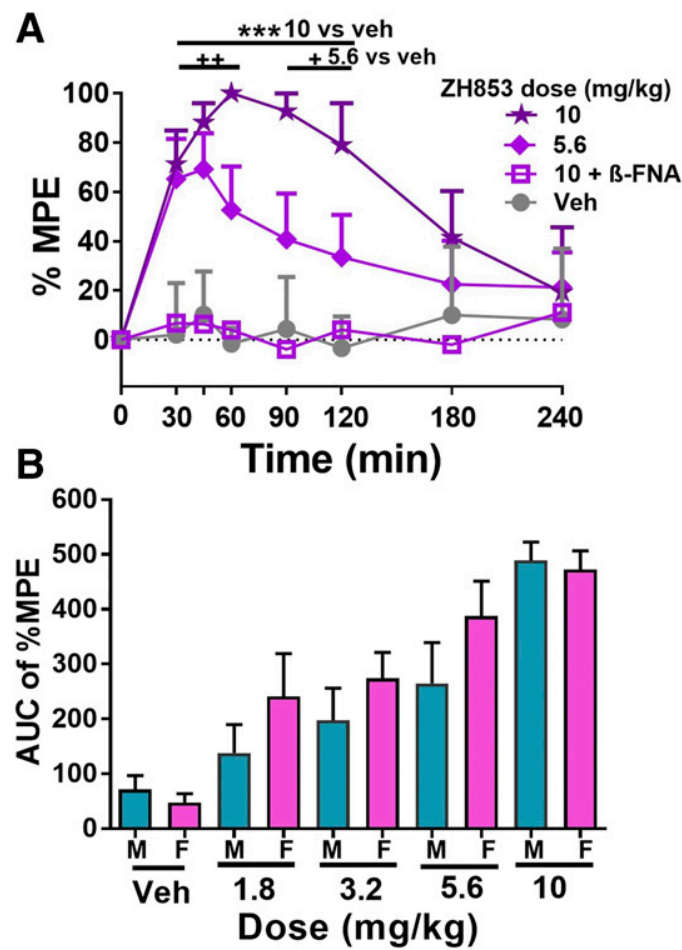

Fig. 3. Antinociceptive effects of ZH853 in the hot-plate (HP) test Latencies of mice to lick or shake the paw were measured at regular intervals and converted to \%MPE. (A) Values show dose-dependent HP antinociception produced in males by ZH853 that was attenuated by the MOR-selective irreversible antagonist $\beta$ FNA $(40 \mathrm{mg} / \mathrm{kg}$, s.c. $) .{ }^{+},{ }^{++} P<$ $0.05,0.01$ for $5.6 \mathrm{mg} / \mathrm{kg}$ compared with vehicle; $* * * P<0.001$ for $10 \mathrm{mg} / \mathrm{kg}$ compared with vehicle. Values after $10 \mathrm{mg} / \mathrm{kg}$ ZH853 $+\beta$ FNA were not different from vehicle. (B) Area under the curve at various doses for both males and females. ANOVA showed a significant effect of dose $F(4,60)=16.61, P<0.0001$, but the effects of sex and the interaction were not significant.

$[F(2,136)=40.4, P<0.0001]$, time $[F(7,136)=6.7, P<0.0001]$, and interaction $[F(14,136)=2.5 P<0.01]$. Significant increases in latencies lasting up to 2 hours were observed for both 5.6 and $10 \mathrm{mg} / \mathrm{kg}$. $\beta$ FNA $(40 \mathrm{mg} / \mathrm{kg}$, s.c.) had no antinociceptive properties alone; however, 24 hours of pretreatment with $\beta$ FNA ( $40 \mathrm{mg} / \mathrm{kg}$, s.c.) reversed the antinociceptive effects of the high dose of ZH853 $(P<0.001)$. ZH853 showed similar dose-dependent efficacy in female DBA mice. Figure $3 \mathrm{~B}$ compares the area under the curve at various doses for both males and females. ANOVA showed a significant effect of dose $F(4,60)=16.61, P<0.0001$, but the effects of sex and the interaction were not significant.

ZH853 Substituted for Morphine with Less Disruption in the Drug- Discrimination Procedure. The DD effects of ZH850, ZH831, and ZH853 were studied in rats trained to discriminate subcutaneous and intravenous injections of morphine from vehicle (see Table 1 for procedural details). Subcutaneous morphine produced dose-dependent responding on the drug-paired lever $\left(\mathrm{ED}_{50}=1.247 \mathrm{mg} / \mathrm{kg}\right)$ that was slightly less potent than intravenous morphine $\left(\mathrm{ED}_{50}=0.879 \mathrm{mg} / \mathrm{kg}\right.$, data not shown $)$, consistent with antinociceptive route of injection differences found in a previous study (South et al., 2009). After approximately 20 sessions, morphine produced $>90 \%$ appropriate drug-lever responding, whereas vehicle produced only $0.6 \%$ drug-lever responding (Fig. 4A). Substitution curves were generated for morphine
(Fig. 4B), ZH850, ZH831, and ZH853 (Fig. 5) in tests in which both levers delivered food. Response rates for food were modestly impaired by the training doses of morphine $(3.2 \mathrm{mg} / \mathrm{kg}$, s.c. and $1.8 \mathrm{mg} / \mathrm{kg}$, i.v.) compared with saline (Fig. 4C). ZH850, ZH831, and ZH853 fully substituted for morphine under both injection procedures, but only morphine $[F(5,29)=9.467$, $P<0.0001$ (Fig. 4D)] and, to a lesser extent, ZH850 $\left[F\left({ }_{5}, 26\right)=\right.$ $3.216, P=0.0216$ (Fig. 5A)] reduced response rates compared with vehicle. Response rates were not impaired by ZH831 $[F(5,28)=1.391, P=0.2578$ n.s. (Fig. $5 \mathrm{~B})]$ or ZH853 $[F(5,29)=$ 2.063, $P=0.0991$ n.s. (Fig. 5C)]. ZH853 response rate impairment scores were the lowest among all compounds tested. Table 2 shows relative $\mathrm{ED}_{50}$ values after bolus or within-session cumulative injections of morphine, ZH850, ZH831, or ZH853. Cumulative injections produced slightly more potent $\mathrm{ED}_{50}$ values for all compounds compared with bolus injections made between sessions.

Comparing the SA data during 12-hour SA sessions from our previous study (Zadina et al., 2016), we found that, at a dose of $1 \mathrm{mg} / \mathrm{kg}$ per infusion, the hourly SA intake of morphine was $\sim 3.5 \mathrm{mg} / \mathrm{kg}$ per hour, relatively higher than the antinociceptive $\mathrm{ED}_{50}(1.27 \mathrm{mg} / \mathrm{kg})$ and the $\mathrm{DD}^{\mathrm{E}} \mathrm{ED}_{50}$ $(0.88 \mathrm{mg} / \mathrm{kg}$ ) (Fig. 6). Comparing the antinociceptive and drug discrimination dose-response curves (left $y$-axis) for ZH853 with SA intake/hour (milligrams per kilogram, right $y$-axis) SA sessions, ZH853 peaked at $1.1 \mathrm{mg} / \mathrm{kg}$ per hour at the $3 \mathrm{mg} / \mathrm{kg}$ per infusion dose, but this was relatively lower than the antinociceptive $\mathrm{ED}_{50}$ and the $\mathrm{ED}_{50}$ for $\mathrm{DD}$. The $\mathrm{SA}$ infusion doses of 1 and $3 \mathrm{mg} / \mathrm{kg}$ per infusion of ZH853 corresponded roughly with the $\mathrm{ED}_{20}$ and $\mathrm{ED}_{80}$ in the $\mathrm{DD}$ model, respectively. Similarly, the $1-\mathrm{mg} / \mathrm{kg}$ per infusion dose corresponded to the antinociceptive $\mathrm{ED}_{20}$, and the $3 \mathrm{mg} / \mathrm{kg}$ per infusion dose produced maximal (100\% MPE) antinociception in tail-flick tests (Fig. 6). Thus, rats self-administered a larger amount of morphine than maximal doses producing antinociception or DD, whereas for ZH853, the hourly SA intake remained below the level producing antinociception and morphine-substitution effects.

\section{Discussion}

This series of studies, together with our previous findings (Zadina et al., 2016), have shown that ZH853 does not produce rewarding effects, despite CNS penetration, as reflected in SA, CPP, and LS paradigms. In addition, changes in VTA DA neurons associated with drugs of abuse like morphine were not observed with ZH853. Drug discrimination tests, however, show that ZH853 and a related EM analog (ZH831) were able to fully substitute for morphine. Since the substitution effects occurred without response rate disruption, ZH831 and ZH853 may have favorable profiles for the treatment of OUD.

In experiment 1, conditioning for 5 days with ZH853 did not induce CPP or locomotor sensitization (LS; Fig. 1) and, after this procedure, ZH853 did not reduce the size of DA cell somas (Fig. 2), whereas morphine produced CPP, LS, and decreased DA cell-soma size in the VTA. The lack of response-rate disruption during DD substitution and evidence that ZH853 does not produce SA, CPP, LS, or DA cell soma morphology alterations indicate a therapeutic range in which $\mathrm{ZH} 853$ substitutes for morphine with reduced abuse liability.

Extending our previous CPP study in which ZH853 was injected over three daily pairings, ZH853 did not produce CPP 
TABLE 1

Training schedule for drug discrimination

\begin{tabular}{llll}
\hline Phase & \multicolumn{1}{c}{ Schedule } & \multicolumn{1}{c}{ Lever for Food } & Stimulus-Light Illuminated \\
\hline $1 \mathrm{a}$ & Food training & Both levers (FR1) & Both \\
$1 \mathrm{~b}$ & Food training & Only left or only right (FR10) & Only correct lever \\
$2 \mathrm{a}$ & Morphine $(3.2 \mathrm{mg} / \mathrm{kg}$ s.c.) training & Only morphine or vehicle lever & Only correct lever \\
$2 \mathrm{~b}$ & Morphine $(3.2 \mathrm{mg} / \mathrm{kg}$ s.c.) training & Only morphine or vehicle lever & Both \\
$2 \mathrm{c}$ & Morphine s.c. testing & Both levers & Both \\
$3 \mathrm{a}$ & Morphine (1.8 mg/kg i.v.) training & Only morphine or vehicle lever & Both \\
$3 \mathrm{~b}$ & Morphine or endomorphin analog i.v. testing & Both levers & Both \\
\hline
\end{tabular}

effects after five daily pairings. One explanation for this may be that locomotor sensitization (LS) did not occur during conditioning sessions with ZH853, whereas morphine induced robust LS effects in addition to CPP. Reinstatement of heroin SA has been associated with the expression of LS since animals that previously SA heroin showed exaggerated locomotor responses upon challenge with heroin, cocaine, and amphetamine compared with controls (De Vries et al., 1999). The lack of LS induced by ZH853 may also explain why ZH853 was not SA in our previous study (Zadina et al., 2016) since most compounds that produce SA and CPP effects also produce LS (Robinson and Berridge, 2001). One exception to this is tramadol, which does not produce LS, but does produce CPP (Tzschentke, 2004) and a low SA response rate (O'Connor and Mead, 2010), indicating that these abuse potential effects are separable. The lack of SA, LS, and CPP by ZH853 is a critical finding because these effects were tested at doses that produced antinociceptive and morphine-discriminative stimulus effects.

After CPP, we analyzed DA cell-soma morphology in these rats since morphine and heroin have been reported to reduce DA cell-soma size in the VTA in postmortem human heroin

A

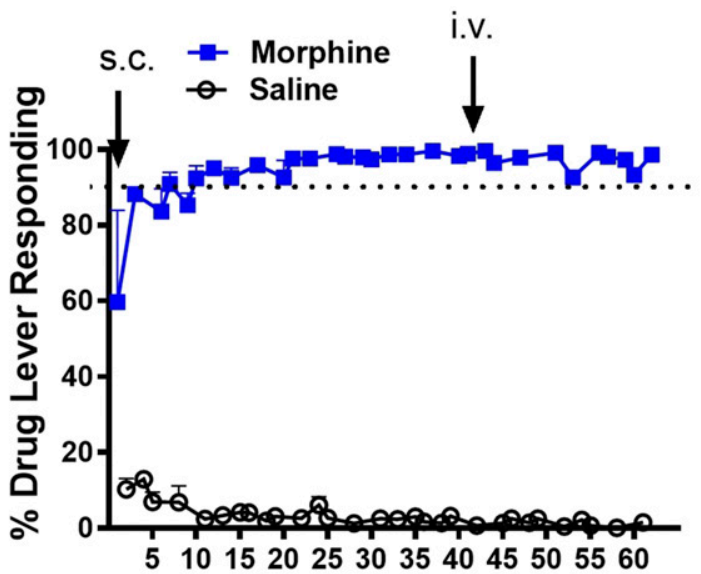

B
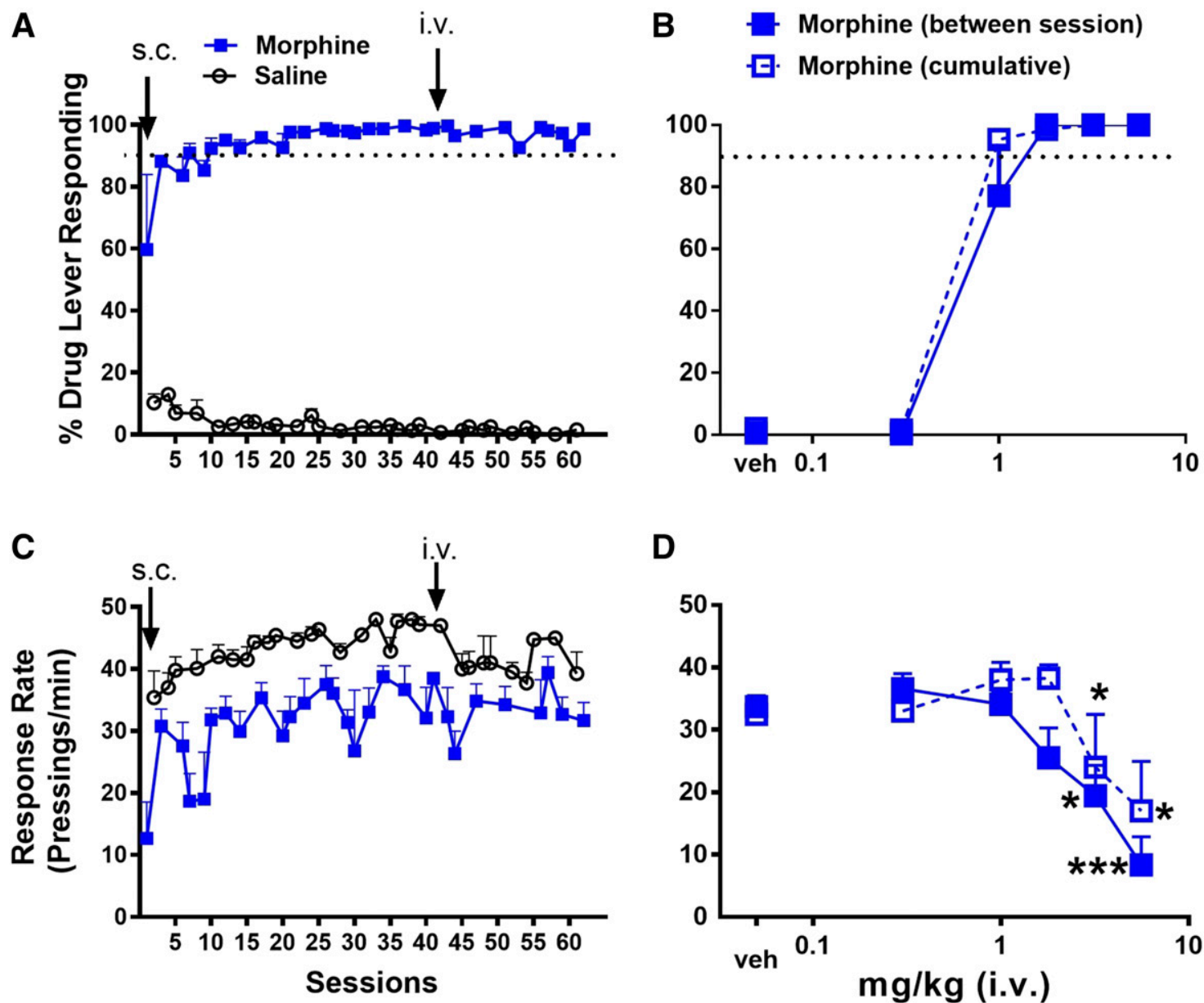

D

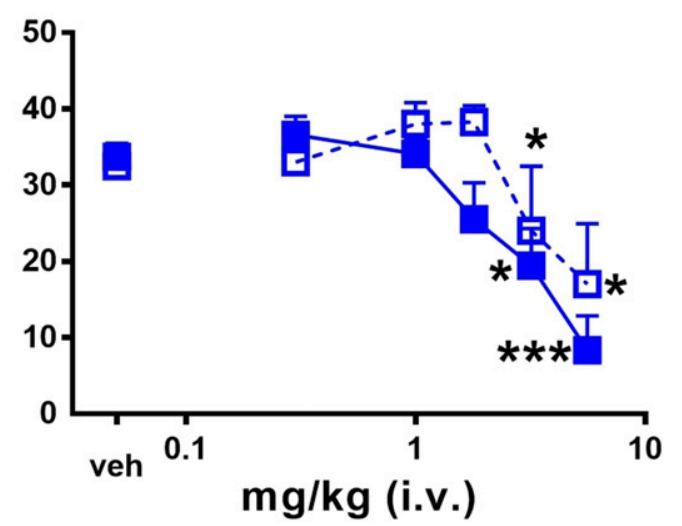

Fig. 4. Morphine discrimination training and substitution testing. (A) Rats were trained to discriminate morphine (3.2 mg/kg, s.c.) from vehicle (subcutaneous) and reached criterion after approximately 20 sessions. Rats were then catheterized for intravenous injections, allowed to recover, and continued training to discriminate morphine $(1.8 \mathrm{mg} / \mathrm{kg}$, i.v.) from vehicle (intravenous) injections. The dotted line in (A) indicates the training criteria of $90 \%$ drug-appropriate responding. (B) During test sessions in which both levers actively delivered food, rats responded dose dependently on the drugpaired lever for intravenous morphine after bolus injections made between sessions or intravenous cumulative injections made within a single session. (C) Response rates for food on the morphine and vehicle levers during morphine discrimination training sessions. Morphine (3.2 mg/kg s.c. and $1.8 \mathrm{mg} / \mathrm{kg}$ i.v.) produced some impairment of responding during training. (D) Morphine disrupted response rates during test sessions at doses $\geq 3.2 \mathrm{mg} / \mathrm{kg}$ after bolus injections and $\geq 5.6 \mathrm{mg} / \mathrm{kg}$ after cumulative injections. ${ }^{*}, * * * P<0.05,0.001$ compared with vehicle. $n=6$. 

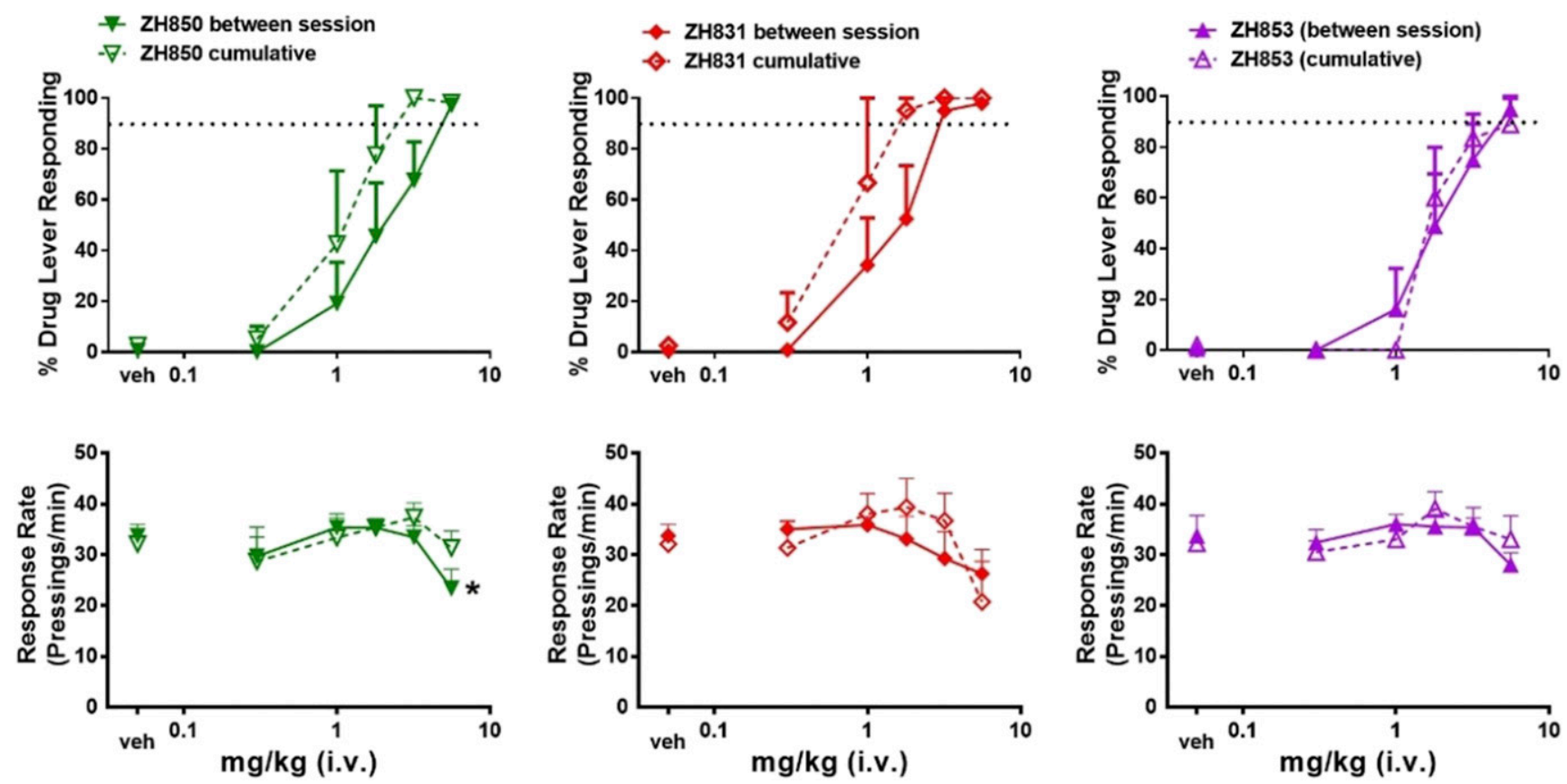

Fig. 5. Discriminative stimulus and response-rate effects of EM analogs in morphine-trained rats. Morphine-appropriate lever responding during test sessions in which ZH850 (A), ZH831 (B), or ZH853 (C) was administered, with bolus injections made between sessions or cumulative injections made within a single session. Bottom panels show response rates for food (pressings/minute) were modestly, but significantly, impaired by between-session injection of ZH850, but not after cumulative injections. ZH831 and ZH853 did not impair response rates under either injection method and fully substituted for morphine. ${ }^{*} P<0.05$ compared with vehicle. $n=6$.

users (Mazei-Robison et al., 2011), rats (Spiga et al., 2003; Russo et al., 2007; Chu et al., 2008), and mice (Mazei-Robison et al., 2011). These pVTA neurons synapse in the nucleus accumbens (NAc) and release DA at median spiny neurons that project to nucleus accumbens and prefrontal cortex regions such as the anterior cingulate cortex (Ikemoto, 2007). Postmortem studies show heroin overdose deaths are associated with reduced dopamine concentration in the nucleus accumbens (Kish et al., 2001) compared with controls. Chronic morphine produces a reward-tolerance effect that coincides with hyperexcitable DA neuron-firing rates, decreased DA release in the NAc, and DA soma size reductions (Sklair-Tavron et al., 1996; Mazei-Robison et al., 2011). Daily injections of morphine $(5.6 \mathrm{mg} / \mathrm{kg})$ sufficed to reduce the area and volume of DA neurons in the pVTA; however, ZH853 did not reduce the size of DA cell somas at any dose (Fig. 2). This dose of morphine $(5.6 \mathrm{mg} / \mathrm{kg})$ did not induce significant CPP, but did shrink the size of DA neurons in the pVTA; so it is possible that tolerance to the rewarding effects of this dose occurred after the five daily injections. For example, a lower dose of morphine $(3.2 \mathrm{mg} / \mathrm{kg})$ did not shrink the size of these DA neurons; however, this dose produced CPP and LS. Overall, these morphologic changes are associated with physiologic, neurochemical, and behavioral adaptations that occur during chronic opioid use. Therefore, the absence of DA morphology alterations after five daily injections of ZH853 further support the behavioral studies that indicate low abuse liability.

The hot plate antinociception induced by ZH853 suggests BBB penetration was achieved and supports our previous BBB penetration data showing that antinociception after peripheral (intravenous) injection is significantly reduced by a centrally administered (i.c.v.) opioid antagonist (Zadina et al., 2016). The use of mice here and rats in earlier studies indicates generality across species. Furthermore, it is wellknown that mice typically require a larger dose than rats, so the $10-\mathrm{mg} / \mathrm{kg}$ maximum dose of ZH853 used in the present study seems appropriate. Taken together, these studies indicate that the lack of rewarding properties of ZH853 is not explained by a lack of CNS penetration.

Although the intravenous catheter patency limited our examination of naloxone sensitivity to the discriminative stimulus effects of the EM analogs, tests in two rats showed reversal by this antagonist (data not shown). Owing to the irreversible nature of $\beta$-funaltrexamine $(\beta \mathrm{FNA})$, we were unable to test this compound during DD test sessions, but since $\beta$ FNA blocked hot-plate antinociception induced by ZH853 (Fig. 3) and receptor binding and in vivo studies show high MOR selectivity (Zadina et al., 2016), we conclude that ZH853 is highly MOR selective and that agonist activity at this receptor likely accounts for both the antinociceptive and discriminative stimulus effects of ZH853.

Rats trained to discriminate morphine from vehicle injections (Fig. 4) dose dependently pressed the morphine-trained lever when preinjected with EM analogs (Fig. 5). Whereas morphine, and to a lesser extent ZH850, significantly decreased response rates during DD test sessions, ZH831 and ZH853 did not decrease response rates during substitution experiments. There are several examples of opioids that substitute for morphine in the DD model, including heroin, buprenorphine, fentanyl, oxycodone, methadone, and methadone's active metabolites (Young et al., 1992; Craft et al., 1999; Beardsley et al., 2004; Vann et al., 2009). A common effect of these opioids is that they disrupt response rates for food reinforcement in the DD model, promote reward behaviors (Mucha et al., 1982; Beardsley et al., 2004; Martin et al., 2007; 


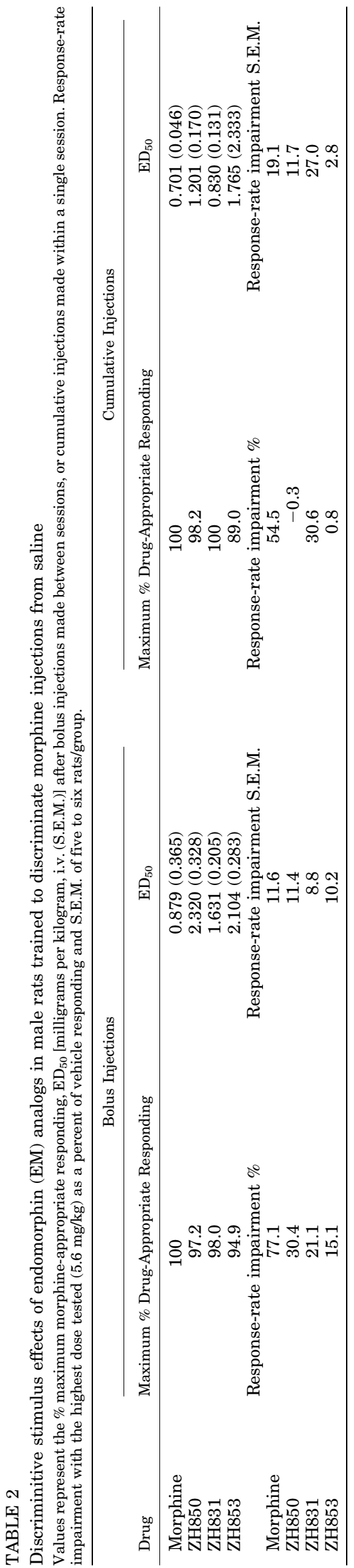

Morphine:

- Antinociception $\mathrm{ED}_{50}=1.273$

-.. Drug discrimination $\mathrm{ED}_{50}=0.879$

Self-administration (SA) intake $/ \mathrm{h}$
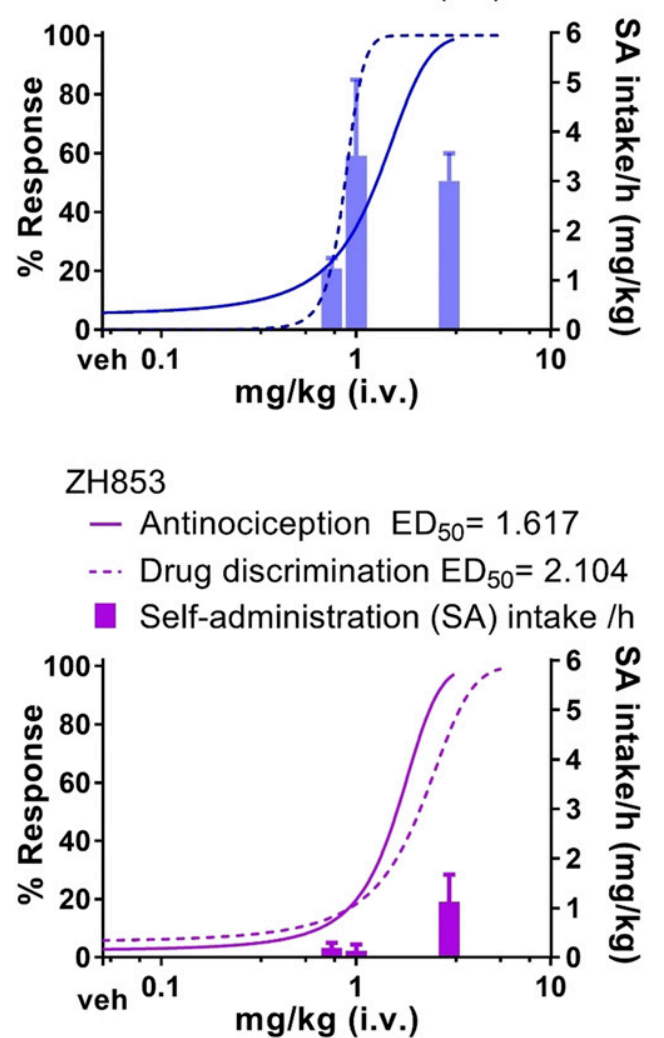

Fig. 6. Comparison of the pharmacodynamic effects of morphine and ZH853. Morphine antinociception and DD dose-response curves (\% response, left $y$-axis) and self-administration SA intake per hour (SA intake milligrams per kilogram, right $y$-axis) during 12-hour SA sessions requiring high FR responding (FR3-5). SA and antinociception data were reproduced from Zadina et al. (2016) with permission.

Zhang et al., 2009), and induce respiratory depression (Lewanowitsch et al., 2004), motor sensitization (Tzschentke, 2004), cognitive impairment (Hepner et al., 2002), and tolerance after chronic administration (Meltzer et al., 1978). The EM analogs tested here have reduced respiratory depression, reward, motor impairment, and tolerance (Zadina et al., 2016). Presently, ZH850, ZH831, and ZH853 impaired DD response rates by only $30 \%, 21 \%$, and $15 \%$, after bolus infusions, and $0.3 \%, 31 \%$, and $0.8 \%$ after cumulative injections, respectively. Morphine impaired response rates by $77 \%$ and $55 \%$ after bolus or cumulative injections, respectively. Therefore, ZH831 and ZH853 did not disrupt responding at doses that fully substituted for morphine, whereas ZH850 impaired response rates only after bolus, but not after cumulative injections. We chose the $5.6-\mathrm{mg} / \mathrm{kg}$ dose of ZH853 as the maximum dose because of the long antinociceptive duration ( 4.5 hours) produced by this dose, and the fact that this dose of ZH853 substituted for morphine supports the rationale for choosing this maximum dose. The DD effects of ZH831 and ZH853 are consistent with the lack of motor impairment produced by these analogs on the Rotarod after cumulative doses that produced maximum antinociceptive effects in our prior report (Zadina et al., 2016). The long duration of antinociceptive effects 
and reduced tolerance displayed previously by the EM analogs suggest that fewer subsequent doses would be required to maintain morphine-substitution effects (Flugsrud-Breckenridge et al., 2007). Overall, all EM analogs tested here produced morphine discriminative stimulus effects that coincided with less response-rate disruption, an effect that could have a favorable outcome for the treatment of OUD. Given that morphine has numerous physiologic effects, we do not know what stimulus is prompting the rats to respond on the morphine-paired lever when injected with ZH853. Perhaps an antinociceptive effect, which has an $\mathrm{ED}_{50}$ below that of the $\mathrm{ED}_{50}$ for $\mathrm{DD}$ (see Fig. 6), is prompting the response. Clinical trials with patient verbal responses may shed light on similarities and differences between ZH853 and morphine that underlie their shared discriminative stimulus effects but differential reinforcing effects. The preclinical data here, however, clearly support the concept that the DD and reinforcing effects are separable.

There are three potential mechanisms by which such a dissociation of analgesic and discriminative stimulus effects from rewarding effects might occur: 1) Pharmacokinetic (PK) factors could contribute to the lack of reinforcing effects produced by ZH853. It is well established that drugs with slower onset and longer duration of action produce fewer reinforcing effects. Of these, the onset after i.v. injection is only marginally slower than that of morphine, but the duration of action is longer and could contribute to the differences. 2) A major current focus for differential agonist effects is on biased agonism, particularly G-protein activation versus $\beta$-arrestin recruitment. Preliminary studies indicate that $\mathrm{ZH} 853$ is a full agonist for G-protein activation and moderately recruits $\beta$-arrestin. This does not fit current descriptions of biased agonism regarding these two signaling processes. Most current studies of biased agonism focus on G-protein biased agonists, that is, agonists with high G-protein efficacy and extremely low $\beta$-arrestin recruitment to approximate $\beta$-arrestin knockout effects. Favorable effects of very low or absent $\beta$-arrestin recruitment are reduced respiratory depression, enhanced analgesia, and reduced gastrointestinal dysfunction. Far less attention is given, however, to the demonstration that $\beta$-arrestin knockout mice displayed an increased sensitivity to the rewarding effects of morphine, including increased CPP and striatal dopamine release compared with wild-type mice (Bohn et al., 2003). It is therefore not surprising, given the lack of rewarding effects $(\mathrm{CPP}, \mathrm{SA}$, and LS) of our analogs, that $\beta$-arrestin recruitment is not reduced relative to morphine (preliminary observation). In addition, the analogs show low respiratory depression despite $\beta$-arrestin recruitment, indicating that low $\beta$-arrestin recruitment is sufficient, but not necessary, for low respiratory depression. Numerous cellular signaling processes are evoked by $\mu$-agonists, and further studies may reveal signaling biases that are critical for the uniquely favorable effects of ZH853 other than the relative G-protein/ $\beta$-arrestin signaling.

In addition to PK factors and signaling biases at the $\mu$-receptor, a third potential mechanism is the fact that differential glial activation contributes to differences in the effects of the analogs relative to morphine-like compounds. We have shown that several endomorphin analogs do not activate glia under conditions where morphine does (Zadina et al., 2016). This finding correlated with reduced tolerance for the analogs. Modulation of glial cells may also play a key role in reward. Several studies have linked glial reactivity to morphineinduced reward behaviors. Morphine-induced CPP was associated with increased expression of Iba1 and pp38 in the NAc (Zhang et al., 2012). Systemic (Hutchinson et al., 2008) and intra-accumbens (Zhang et al., 2012) minocycline blocked morphine-induced CPP and intra-NAc injection of media from cultured astrocytes potentiated CPP for morphine (Narita et al., 2006). Morphine-induced glial changes have also been shown to contribute to reward tolerance (Taylor et al., 2016). Thus, glial activation after morphine is associated with impairment of analgesia, increases in analgesic tolerance, and facilitation of reward and reward tolerance. The lack of glial activation by ZH853 is consistent with the relative lack of these behavioral effects compared with morphine. Thus, the presence of DD and potent analgesia in the absence of reward may be mediated, in part, by the unique glial profile of ZH853.

OUD is a difficult-to-manage disorder that often requires chronic daily treatment with long-acting opioid drugs that may themselves produce self-administrations and behaviorally disruptive effects. ZH831 and ZH853 did not produce reinforcing effects in SA/CPP procedures, nor did these compounds disrupt response rates at doses that substituted for morphine. The antinociceptive effects of ZH853 were blocked by $\beta \mathrm{FNA}$, indicating MOR selectivity of this compound. Although morphine reduced the area and volume of DA cell somas in the VTA, ZH853 did not produce this effect. It should be emphasized that the morphine-substitution effects of ZH853 would have predicted that this analog would produce self-administrations; however, this was not the case. ZH853 was not self-administered, even under 12-hour access conditions, nor did it produce CPP or LS, so the reinforcing effects of a compound can be dissociated from its morphine-discriminative stimulus effects. The low abuse liability profile and potent morphine-substitution effects of EM analogs shown here, particularly ZH853, indicate that they could significantly improve treatment of this disorder.

\section{Disclosure}

The contents do not represent the views of the U.S. Department of Veterans Affairs or the United States Government. J.E.Z. is an inventor on patents covering the compounds characterized here. These are assigned under joint agreement to the Department of Veterans Affairs and Tulane University School of Medicine.

\section{Acknowledgments}

The authors thank Sharon Luc for technical assistance and Melita B. Fasold for reviewing the manuscript.

\section{Authorship Contributions}

Participated in research design: Nilges, Zadina.

Conducted experiments: Nilges, Cable, Arens, Laurent, Vafiades. Performed data analysis: Nilges, Zadina.

Wrote or contributed to the writing of the manuscript: Nilges, Zadina.

\section{References}

Ator NA (2002) Relation between discriminative and reinforcing effects of midazolam, pentobarbital, chlordiazepoxide, zolpidem, and imidazenil in baboons. Psychopharmacology (Berl) 163:477-487.

Beardsley PM, Aceto MD, Cook CD, Bowman ER, Newman JL, and Harris LS (2004) Discriminative stimulus, reinforcing, physical dependence, and antinociceptive 
effects of oxycodone in mice, rats, and rhesus monkeys. Exp Clin Psychopharmacol 12:163-172.

Bohn LM, Gainetdinov RR, Sotnikova TD, Medvedev IO, Lefkowitz RJ, Dykstra LA and Caron MG (2003) Enhanced rewarding properties of morphine, but not cocaine, in $\beta$ (arrestin)-2 knock-out mice. J Neurosci 23:10265-10273.

Bordia T, Hrachova M, Chin M, McIntosh JM, and Quik M (2012) Varenicline is a potent partial agonist at $\alpha 6 \beta 2 *$ nicotinic acetylcholine receptors in rat and monkey striatum. J Pharmacol Exp Ther 342:327-334.

Chapman CR, Casey KL, Dubner R, Foley KM, Gracely RH, and Reading AE (1985) Pain measurement: an overview. Pain 22:1-31.

Chu NN, Xia W, Yu P, Hu L, Zhang R, and Cui CL (2008) Chronic morphine-induced neuronal morphological changes in the ventral tegmental area in rats are reversed by electroacupuncture treatment. Addict Biol 13:47-51.

Comer SD, Sullivan MA, and Walker EA (2005) Comparison of intravenous buprenorphine and methadone self-administration by recently detoxified heroindependent individuals. J Pharmacol Exp Ther 315:1320-1330.

Craft RM, Heideman LM, and Bartok RE (1999) Effect of gonadectomy on discriminative stimulus effects of morphine in female versus male rats. Drug Alcohol Depend 53:95-109.

De Vries TJ, Schoffelmeer AN, Binnekade R, and Vanderschuren LJ (1999) Dopaminergic mechanisms mediating the incentive to seek cocaine and heroin following long-term withdrawal of IV drug self-administration. Psychopharmacology (Berl) 143:254-260.

Flugsrud-Breckenridge MR, Gevirtz C, Paul D, and Gould HJ III (2007) Medications of abuse in pain management. Curr Opin Anaesthesiol 20:319-324.

Hepner IJ, Homewood J, and Taylor AJ (2002) Methadone disrupts performance on the working memory version of the Morris water task. Physiol Behav 76:41-49.

Hutchinson MR, Northcutt AL, Chao LW, Kearney JJ, Zhang Y, Berkelhammer DL, Loram LC, Rozeske RR, Bland ST, Maier SF, et al. (2008) Minocycline suppresses morphine-induced respiratory depression, suppresses morphine-induced reward, and enhances systemic morphine-induced analgesia. Brain Behav Immun 22: $1248-1256$

Ikemoto S (2007) Dopamine reward circuitry: two projection systems from the ventral midbrain to the nucleus accumbens-olfactory tubercle complex. Brain Res Brain Res Rev 56:27-78.

Jones JD, Madera G, and Comer SD (2014) The reinforcing and subjective effects of intravenous and intranasal buprenorphine in heroin users. Pharmacol Biochem Behav 122:299-306.

Kish SJ, Kalasinsky KS, Derkach P, Schmunk GA, Guttman M, Ang L, Adams V, Furukawa Y, and Haycock JW (2001) Striatal dopaminergic and serotonergic markers in human heroin users. Neuropsychopharmacology 24:561-567.

Krivsky JA, Stoffel EC, Sumner JE, Inman BC, and Craft RM (2006) Role of ventral tegmental area, periaqueductal gray and parabrachial nucleus in the discriminative stimulus effects of morphine in the rat. Behav Pharmacol 17:259-270.

Lewanowitsch T, White JM, and Irvine RJ (2004) Use of radiotelemetry to evaluate respiratory depression produced by chronic methadone administration. Eur $J$ Pharmacol 484:303-310.

Martin TJ, Kim SA, Buechler NL, Porreca F, and Eisenach JC (2007) Opioid selfadministration in the nerve-injured rat: relevance of antiallodynic effects to drug consumption and effects of intrathecal analgesics. Anesthesiology 106:312-322.

Mazei-Robison MS, Koo JW, Friedman AK, Lansink CS, Robison AJ, Vinish M, Krishnan V, Kim S, Siuta MA, Galli A, et al. (2011) Role for mTOR signaling and neuronal activity in morphine-induced adaptations in ventral tegmental area dopamine neurons. Neuron 72:977-990.

Mazei-Robison MS and Nestler EJ (2012) Opiate-induced molecular and cellular plasticity of ventral tegmental area and locus coeruleus catecholamine neurons. Cold Spring Harb Perspect Med 2:a012070.

Meltzer LT, Moreton JE, and Khazan N (1978) Electroencephalographic and behavioral tolerance and cross-tolerance to morphine and methadone in the rat Toxicol Appl Pharmacol 45:837-844.

Mucha RF, van der Kooy D, O'Shaughnessy M, and Bucenieks P (1982) Drug reinforcement studied by the use of place conditioning in rat. Brain Res 243:91-105.

Narita M, Miyatake M, Narita M, Shibasaki M, Shindo K, Nakamura A, Kuzumaki N, Nagumo Y, and Suzuki T (2006) Direct evidence of astrocytic modulation in the development of rewarding effects induced by drugs of abuse. Neuropsychopharmacology 31:2476-2488.
O'Connor EC and Mead AN (2010) Tramadol acts as a weak reinforcer in the rat selfadministration model, consistent with its low abuse liability in humans. Pharmacol Biochem Behav 96:279-286.

Paxinos G and Watson C (2007) The Rat Brain in Stereotaxic Coordinates, Academic Press/Elsevier, Amsterdam.

Robinson TE and Berridge KC (2001) Incentive-sensitization and addiction. Addiction 96:103-114.

Russo SJ, Bolanos CA, Theobald DE, DeCarolis NA, Renthal W, Kumar A, Winstanley CA, Renthal NE, Wiley MD, Self DW, et al. (2007) IRS2-Akt pathway in midbrain dopamine neurons regulates behavioral and cellular responses to opiates. Nat Neurosci 10:93-99.

Sklair-Tavron L, Shi WX, Lane SB, Harris HW, Bunney BS, and Nestler EJ (1996) Chronic morphine induces visible changes in the morphology of mesolimbic dopamine neurons. Proc Natl Acad Sci USA 93:11202-11207.

South SM, Edwards SR, and Smith MT (2009) Antinociception versus serum concentration relationships following acute administration of intravenous morphine in male and female Sprague-Dawley rats: differences between the tail flick and hot plate nociceptive tests. Clin Exp Pharmacol Physiol 36:20-28.

Spiga S, Serra GP, Puddu MC, Foddai M, and Diana M (2003) Morphine withdrawalinduced abnormalities in the VTA: confocal laser scanning microscopy. Eur $J$ Neurosci 17:605-612.

Steinpreis RE, Rutell AL, and Parrett FA (1996) Methadone produces conditioned place preference in the rat. Pharmacol Biochem Behav 54:339-341.

Swedberg MD (2016) Drug discrimination: a versatile tool for characterization of CNS safety pharmacology and potential for drug abuse. J Pharmacol Toxicol Methods 81:295-305.

Taylor AM, Castonguay A, Ghogha A, Vayssiere P, Pradhan AA, Xue L, Mehrabani S, Wu J, Levitt P, Olmstead MC, et al. (2016) Neuroimmune regulation of GABAergic neurons within the ventral tegmental area during withdrawal from chronic morphine. Neuropsychopharmacology 41:949-959.

Tzschentke TM (2004) Reassessment of buprenorphine in conditioned place preference: temporal and pharmacological considerations. Psychopharmacology (Berl) 172:58-67.

Vann RE, Wise LE, Varvel SA, Philibin SD, Walentiny DM, and Porter JH (2009) Route of administration influences substitution patterns in rats trained to discriminate methadone vs. vehicle. Drug Alcohol Depend 103:124-130.

Varner KJ, Daigle K, Weed PF, Lewis PB, Mahne SE, Sankaranarayanan A, and Winsauer PJ (2013) Comparison of the behavioral and cardiovascular effects of mephedrone with other drugs of abuse in rats. Psychopharmacology (Berl) 225: 675-685.

Wade CL, Vendruscolo LF, Schlosburg JE, Hernandez DO, and Koob GF (2015) Compulsive-like responding for opioid analgesics in rats with extended access. Neuropsychopharmacology 40:421-428.

Young AM, Masaki MA, and Geula C (1992) Discriminative stimulus effects of morphine: effects of training dose on agonist and antagonist effects of mu opioids. $J$ Pharmacol Exp Ther 261:246-257.

Zadina JE, Hackler L, Ge LJ, and Kastin AJ (1997) A potent and selective endogenous agonist for the $\mu$-opiate receptor. Nature 386:499-502.

Zadina JE, Nilges MR, Morgenweck J, Zhang X, Hackler L, and Fasold MB (2016) Endomorphin analog analgesics with reduced abuse liability, respiratory depression, motor impairment, tolerance, and glial activation relative to morphine. Neuropharmacology 105:215-227.

Zhang XQ, Cui Y, Cui Y, Chen Y, Na XD, Chen FY, Wei XH, Li YY, Liu XG, and Xin WJ (2012) Activation of p38 signaling in the microglia in the nucleus accumbens contributes to the acquisition and maintenance of morphine-induced conditioned place preference. Brain Behav Immun 26:318-325.

Zhang Y, Picetti R, Butelman ER, Schlussman SD, Ho A, and Kreek MJ (2009) Behavioral and neurochemical changes induced by oxycodone differ between adolescent and adult mice. Neuropsychopharmacology 34:912-922.

Address correspondence to: James E. Zadina, Southeast Louisiana Veterans Health Care System and the Departments of Medicine, Neuroscience, and Pharmacology, Tulane University School of Medicine, 1430 Tulane Avenue \#8516, New Orleans, LA 70112. E-mail: jzadina@tulane.edu 